\title{
Sobre Milk y los derechos del colectivo LGBT
}

A propósito de la película de Gus Van Sant del año 2008, este texto se aproxima a la vida de Harvey Milk. Gracias a personas como este político, la protección de los derechos LGBT (es decir, las leyes que buscan la igualdad dentro del colectivo LGBT y la tipificación de los delitos de odio) ha empezado a tenerse en cuenta en muchos ordenamientos jurídicos del mundo. Lamentablemente, su protección sigue generando un debate que muchos países no han querido abordar.

Aida Oliete León ${ }^{1}$

${ }^{1}$ Abogada egresada de la Universidad de Oviedo.

\section{Anotaciones iniciales}

El odio es muy pernicioso, cala dentro de las personas y se alimenta de la ignorancia de quienes necesitan algún culpable para sentirse mejor. En nuestra sociedad, sigue habiendo muchos colectivos oprimidos, aunque algunos han empezado a liberarse. Sería una hipocresía decir que homosexuales y heterosexuales están sujetos a los mismos prejuicios y reciben el mismo trato en todos los países del mundo.

Son muchas las películas que abordan la marginalización a las personas homosexuales. La serie Pose, emitida por HBO, retrata, en su primer episodio, el rechazo de unos padres a su hijo homosexual que soñaba con ser bailarín, por lo que el hijo es echado de casa. ¿Sus argumentos?: "no es natural", "es un pecado", "está mal”... Estos prejuicios se repiten en la película Oraciones para Bobby (Prayers for Bobby, Russell
Foto:

Milk

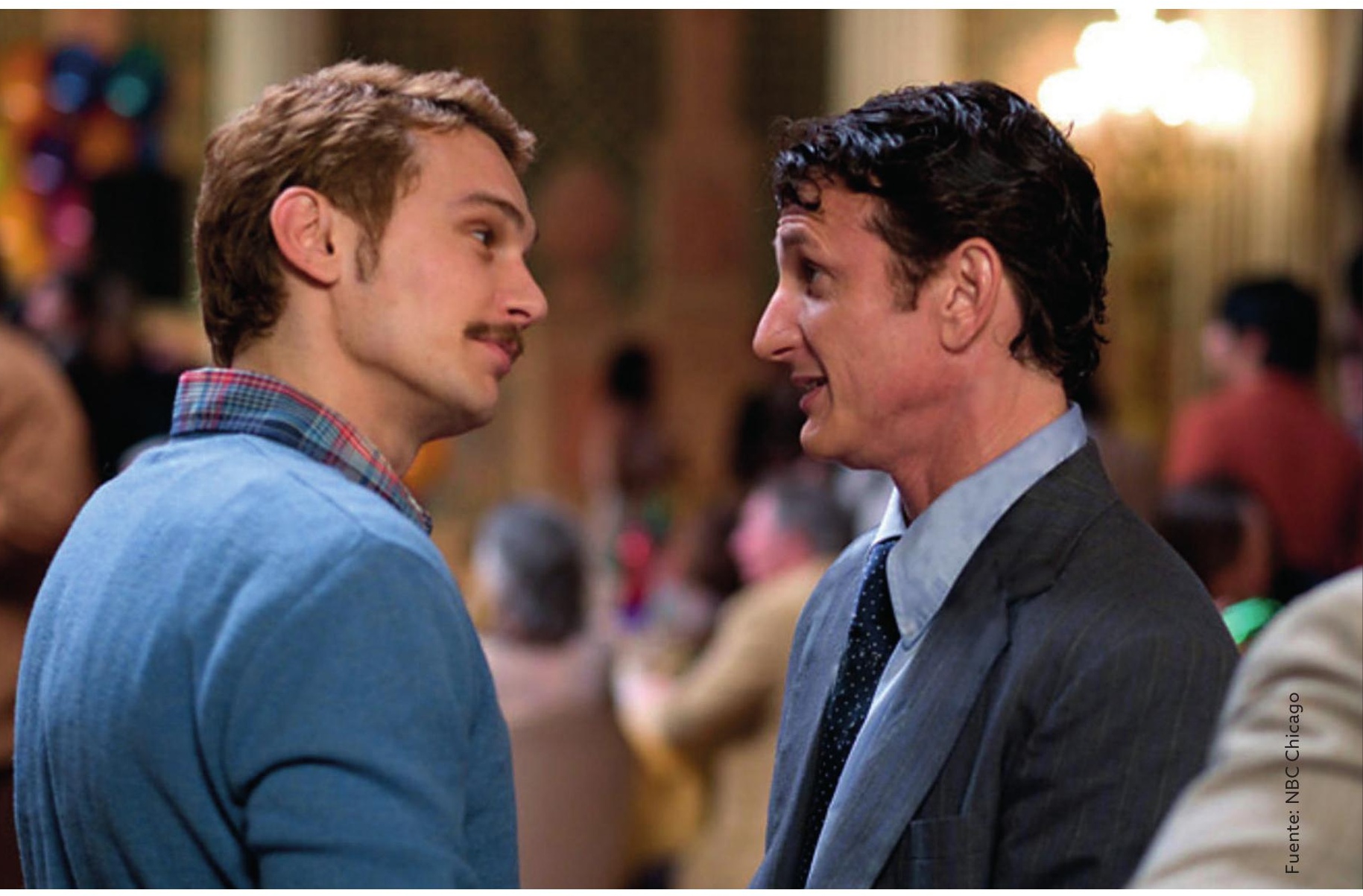


Mulcahy, 2009), protagonizada por una madre que hace lo imposible por "curar" la homosexualidad de su hijo, convencida de que su orientación sexual es algo malo. La mujer convence a su hijo para visitar a un terapeuta que lo pueda tratar; este lo acosa hasta que Bobby, en su desesperación, no ve más salida que el suicidio.

Euphoria (2019), otro de los éxitos de HBO, incluye el conflicto latente de un chico que sufre por no atreverse a aceptar su homosexualidad: aunque no llega a aclararse su orientación sexual en toda la temporada, varias escenas nos hacen pensar que su sufrimiento puede estar motivado por esta razón. Estas producciones abordan el sufrimiento que algunas personas atraviesan por el hecho de sentirse excluidas de la sociedad y de pensar que su orientación sexual puede afectar a quienes tienen a su alrededor.

En Estados Unidos, la situación de este colectivo no era mucho mejor antes de que Harvey Milk fuera elegido para ostentar un cargo público. Las protestas de Stonewell se saldaron con varios heridos y una fuerte y violenta represión policial. Sin embargo, esta revuelta supuso un punto de inflexión que permitió a muchos homosexuales reivindicar sus derechos con más libertad.

Durante la década de 1970, en la que transcurre la historia de la película Milk de Gus Van Sant, la homosexualidad era considerada un delito en casi todo el país y aunque, poco a poco, estas prohibiciones se fueron revocando, las diferencias de unos estados a otros aún eran más que considerables ${ }^{2}$.

El auge de determinados pensamientos en algunos países está dando lugar a que prejuicios que ya creíamos olvidados vuelvan a surgir. Desde que Trump y otros líderes ostentan cargos políticos, muchas personas se han negado a confesar su orientación sexual; de hecho, según The Trevor Project (asociación dedicada a prestar ayuda a jóvenes del colectivo LGBTQ), el día después de su elección como presidente recibieron más llamadas que en todo el año anterior ${ }^{3}$.

\section{El personaje Milk}

La película sobre Harvey Milk refleja perfectamente todo lo que este tuvo que luchar hasta poder ayudar a aquellas personas que se sentían tristes o amenazadas por su condición. Uno de los momentos más desgarradores de la película se produce cuando un chico de unos catorce años lo llama para decirle que se quiere suicidar, que sus padres quieren llevarlo a una terapia de conversión porque consideran que está enfermo. Harvey Milk le aconseja huir, le dice que no hay nada malo en él, pero cuando vemos el encuadre completo descubrimos que el chico está en silla de ruedas y difícilmente podrá escapar de aquella situación. Lo más grave de todo es que todavía hay personas que defienden esas terapias: todavía en pleno 2019 hay gente que sigue acusando a los miembros del colectivo LGBTI de querer acabar con la familia y hacer daño a la sociedad, y lo más grave es que algunas de esas personas llegan a cargos políticos.
DURANTE LA DÉCADA DE 1970, EN LA QUE TRANSCURRE LA HISTORIA DE LA PELÍCULA MILK DE GUS VAN SANT, LAHOMOSEXUALIDAD ERA CONSIDERADA UN DELITO EN CASI TODO EL PAÍS Y AUNQUE, POCO A POCO, ESTAS PROHIBICIONES SE FUERON REVOCANDO, LAS DIFERENCIAS DE UNOS ESTADOS A OTROS AÚN ERAN MÁS QUE CONSIDERABLES.

\begin{abstract}
Esta película comienza con el protagonista contando su historia en primera persona. Grabando algunas de sus reflexiones, reconoce que la mayoría de las cosas que ha hecho han sido pensando en el movimiento gay. Más adelante reconoce que hasta los cuarenta años no había hecho nada de lo que se sintiera especialmente orgulloso; es entonces, una vez instalado en el barrio Castro, cuando convence a sus amigos y conocidos de no frecuentar los comercios y locales que discriminaban a los homosexuales. Entonces empieza a desarrollar su activismo político, comienza a involucrarse con las cuestiones políticas de su ciudad de un modo más comprometido.
\end{abstract}

En Castro conoce a una serie de personas que, intrigadas por su actividad, comienzan a ayudarlo desinteresadamente como Clive, un chico al que conoce por casualidady, a pesar de rechazar la petición inicial de colaborar con él, acaba convirtiéndose en un pilar central de su movimiento. En una escena, Clive le confiesa lo conmocionado que se sintió cuando al viajar a España descubrió la represión que aún existía contra el colectivo homosexual en esos años.

Aunque la homosexualidad no estaba catalogada como delito en el Código Penal español de 1944, la moral católica impo- 
nente y su persecución por otras vías legales hacían que la mayoría de los homosexuales no se atreviese a confesar su condición sexual. Años después, la Ley de Vagos y Maleantes incluyó a los homosexuales entre las personas con un comportamiento considerado antisocial. En cuanto a las terapias de conversión, debemos tener en cuenta lo establecido en la Ley de Peligrosidad y Rehabilitación Social ${ }^{4}$, que pretendía sentar las bases para "curar" la homosexualidad. Por ese motivo se crearon dos penales en las que se destinaron a los presos cuya orientación se debía tratar.

\section{Entre la empatía y el silencio}

Como bien lo cuenta la película, pasó mucho tiempo antes de que Harvey fuese elegido para ostentar un cargo público, pero nunca dejó de luchar: tenía muy claro que sus ideas estaban basadas en la empatía y que no podía conseguirse nada bueno sin promover la educación. Por el contrario, personas como la cantante y activista Anita Bryant - quien aparece en un metraje de archivo al interior de la cinta-y sus seguidores tenían un discurso profundamente homófobo, que incentivaba las creencias más retrógradas de la sociedad. Aunque parezca mentira, sigue existiendo gente cuya mentalidad asume ese tipo de mensajes sin pararse a pensar el daño que estos pueden llegar a causar.

El miedo en el personaje interpretado por Sean Penn no se basaba solo en lo que pudiera pasarle a él: reconoció que todos sus novios habían intentado suicidarse y él, sintiéndose

Foto: culpable, decía que durante muchísimos años Milk había ocultado a su familia y amigos su verda- dera condición sexual. En aquellos tiempos muchísima gente vivía intentando negar u ocultar quiénes eran y muchos lo hacían no solo por miedo a ser rechazados por su familia, sino porque sabían que se arriesgaban a ser despedidos de su trabajo o a estar expuestos a situaciones de violencia que posiblemente no se investigarían con seriedad. En ese sentido, llama la atención que el asesino de Harvey Milk, como bien lo cuenta la película, cumpliera cinco años en la cárcel y luego fuera liberado. Eso hace suponer que, si la víctima hubiera sido otra, el criminal no hubiera disfrutado del privilegio de esa brevísima encarcelación.

La condición o identidad sexual de una persona no puede suponer un motivo de exclusión: la ignorancia puede hacer mucho daño y esta solo puede superarse a través de la educación, de la empatía. Mientras sigamos aceptando con normalidad que ciertas personas sean marginadas por cuestiones de sexo, raza u orientación sexual, estaremos formando parte de una injusticia que nos hará cómplices silenciosos de su continuidad.

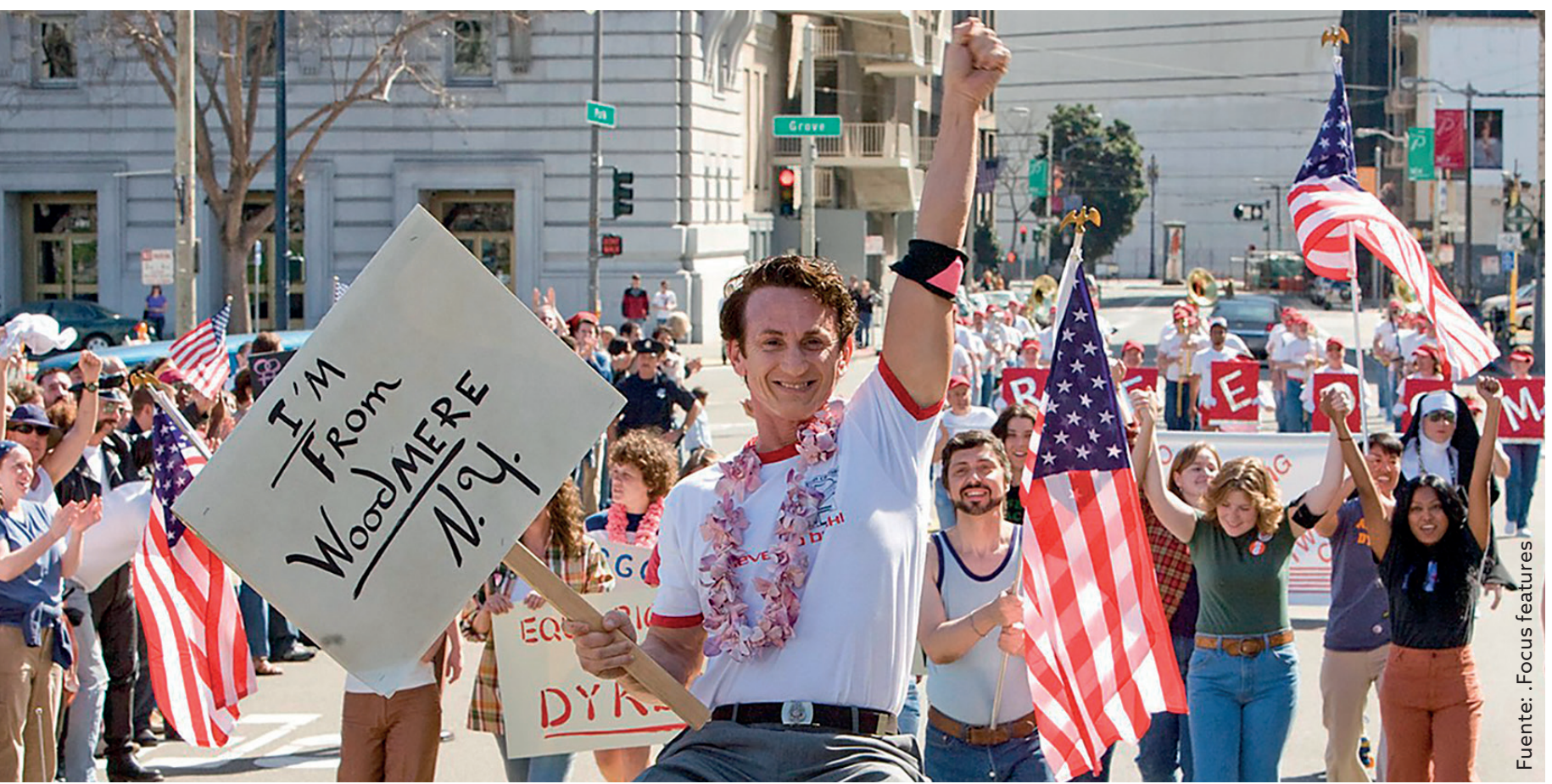

